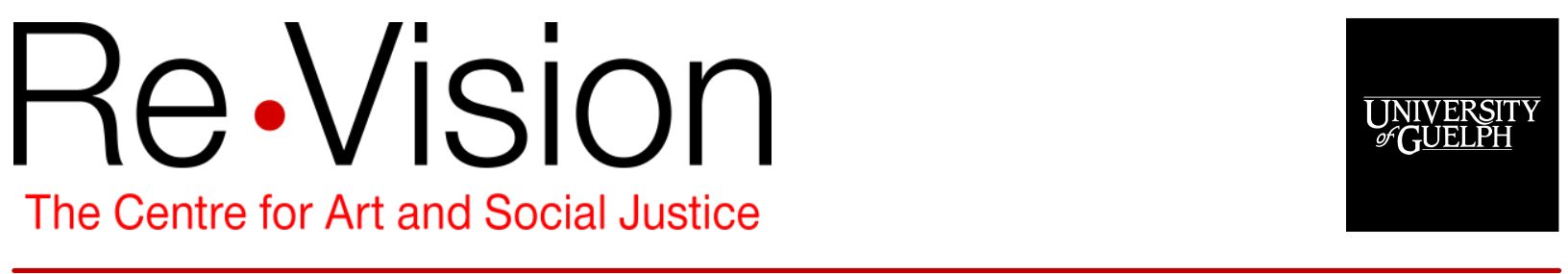

\title{
The primacy of discourse in the study of gender in family therapy
}

\author{
Olga Sutherland \\ University of Guelph \\ Andrea LaMarre \\ University of Guelph \\ Carla Rice \\ University of Guelph
}

This is the peer reviewed version of the following article: Sutherland, O., LaMarre, A., \& Rice, C. (2017). The primacy of discourse in the study of gender in family therapy. Family Process, 56(3), 669-685, which has been published in final form at https://doi.org/10.1111/famp.12294. This article may be used for non-commercial purposes in accordance with Wiley Terms and Conditions for Use of Self-Archived Versions.

\section{Recommended citation:}

Sutherland, O., LaMarre, A., \& Rice, C. (2017). The primacy of discourse in the study of gender in family therapy. Family Process, 56(3), 669-685. https://doi.org/10.1111/famp.12294 


\section{The Primacy of Discourse in the Study of Gender in Family Therapy}

Olga Sutherland, Andrea LaMarre, and Carla Rice

Special thanks to Lorna Martin and journal reviewers for their helpful comments.

\section{Abstract}

Family therapists and scholars increasingly adopt poststructural and postmodern conceptions of social reality, challenging the notion of stable, universal dynamics within family members and families and favoring a view of reality as produced through social interaction. In the study of gender and diversity, many envision differences as social constructed rather than as "residing" in people or groups. There is a growing interest in discourse or people's everyday use of language and how it may reflect and advance interests of dominant groups in a society. Despite this shift from structures to discourse, therapists struggle to locate the dynamics of power in concrete actions and interactions. By leaving undisturbed the social processes through which gendered and other subjectivities and relations of power are produced, therapists may inadvertently become complicit in the very dynamics of power they seek to undermine. In this article, we argue that discourse analysis can help family therapy scholars and practitioners clarify the link between language and power. We present published examples of discourse analytic studies of gender and sexism and examine the relevance of these ideas for family therapy practice and research.

Keywords 
Discourse; Discourse Analysis; Gender; Diversity; Power; Family Therapy; Social Constructionism

Discourse is not simply that which translates struggles or systems of domination, but is the thing for which and by which there is struggle, discourse is the power which is to be seized (Foucault, 1981, p. 52).

Foucault's introductory quote captures this article's main tenet that language is the central site in the production and reproduction of gender and gender-based oppression. The shift in the field of family therapy to conceptualizing gender and gendered power as socially constructed (Dickerson, 2013; Knudson-Martin, 2015) has not been accompanied by developments and applications of social constructionist or discursive methods of inquiry. Conceptions of gender as produced through social interaction and with reference to broader cultural systems of meaning are not accompanied by analyses of how, specifically, dominant gender identities, differences, and hierarchies are discursively constituted and challenged. It is this inconsistency and delay in adopting discourse analytic (discursive) methods, distinctly concerned with how phenomenaincluding gender and gendered power-are constructed through discourse, that we explore in this article, along with suggestions for remedying the situation. Our overall aim is to stress the significance of discourse and promote the use of discursive inquiry within family therapy, particularly among constructionist gender and diversity scholars and practitioners. We encourage family therapy scholars to use discourse analytic or discursive approaches and practitioners to read more discursive studies. To diversify and strengthen research to ensure that the field is better equipped to 
address the complex needs and challenges of a diverse society, it is important that scholars strive to expand their research toolbox and adopt promising research frameworks. We address family therapy scholarship, as the inconsistency we discuss is particularly notable in this area, although our arguments also apply more broadly to the study of family relations within family therapy.

We are informed by social constructionist and postmodern feminist perspectives and have had an ongoing interest in discourse and its link to gender and power, including in the context of family therapy (Sutherland, 2007; Sutherland, LaMarre, Rice, Hardt, \& Jeffery, 2016; Sutherland, LaMarre, Rice, Hardt, \& Le Couteur, 2017). The first author is a family therapist and the second and third authors are gender scholars. I (OS) am Canadian and the first-generation immigrant from Eastern Europe. I am white, able-bodied, middle-class with working-class roots, bisexual in a relationship with a white heterosexual man, cisgender woman in my early 40s. I (AL) am a young, white, Canadian, middle-class, cisgender, heterosexual, single woman. I suffer from chronic back pain and have recovered from an eating disorder. I (CR) am an aging, white, Canadian, affectively working-class, financially middle-class, episodically disabled, queer femme in a committed relationship with an Indigenous woman and three adult Indigenous step (our preferred language is "faux") children, and embedded in a vibrant, politicized, urban Aboriginal community. Our positions of marginality related to gender, sexuality, disability, ethnicity, and Indigeneity have fueled our commitment to social justice and desire to challenge stereotyping and exclusion in institutions and communities, including in the context of family therapy. 
We begin the article by discussing the origins of the field's concern with discourse, including in the study of gender and other socially constructed differences. We then explore a disconnect we have observed between how gender is increasingly theorized in the field and how it is studied. Subsequently, we offer a brief overview of discourse analytic methodologies and examples of their application to the study of gender and oppression. We conclude by examining the relevance of these ideas for family therapy practice and research.

\section{Turn to Discourse}

Family therapists first stressed the significance of discourse in the latter part of the 20th century, when they began applying social constructionist and related (e.g., postmodern, poststructural, feminist, critical) insights to family therapy (Anderson, 1997; Hare-Mustin, 1994; McNamee \& Gergen, 1992; Weingarten, 1991; White \& Epston, 1990).

Discourse can be defined as a "system of statements which constructs an object" (Parker, 1992, p. 5) or "ways of seeing the world, often with reference to relations of power" (Sunderland, 2004, p. 6). The application of constructionist ideas marked a "turn to discourse" in family therapy or "a shift from a representational to a constitutive concept of language: knowledge [of social phenomena] became understood as relationally created in communicative praxis" (De Haene, 2010, p. 2). Social constructionist, postmodern, or discursive therapists (e.g., narrative, solution-focused, collaborative; see Lock \& Strong, 2012) treat discourse as central to the understanding and practice of family therapy. Using this lens, language gains its meaning through its use in social relations and forms the primary means through which people understand and constitute 
themselves and the world (Gergen, 2009). Accordingly, the attention shifts from the "family" as objectively knowable to the discursive construction of (different versions of) family and the sociohistorical relations of power shaping and constraining local meaning making and interaction. There has been a proliferation of constructionist and related ideas in family therapy since these first entered the field (Anderson, 2012; Combs \& Freedman, 2016; Dickerson, 2013; Lock \& Strong, 2012), including the small but growing body of discourse analytic research (for an overview, see Tseliou, 2013).

The field's uptake of discursive perspectives is particularly notable in the area of gender and other dimensions of sociocultural diversity. There is an emerging consensus that gender/diversity and hierarchies are socially constructed (Dickerson, 2013; Falicov, 2010; Knudson-Martin, 2013, 2015). Rather than seeing gender as something that naturally flows from a sexed body, constructionists attend to and explore gendered discourse (Dickerson, 2013; Hare-Mustin, 1994; Keeling, Butler, Green, Kraus, \& Palit, 2010; Maciel, van Putten, \& Knudson-Martin, 2009). Gendered discourse is a "way of seeing the world as it relates to gender. Discourses are usually not stated explicitly but need to be inferred through the ways that particular social groups are represented or through generalizations and assumptions that are embedded in statements" (Baker, 2016, p. 138). Simply put, gendered discourse concerns how gender and gender relations are represented (and enacted) in day-to-day life. Emphasizing both the constructed and constructive nature of discourse (Potter \& Hepburn, 2008), constructionists view gendered discourse as: (a) constructed or assembled by people using a range of discursive or sociolinguistic practices (e.g., word 
choice, particular ways of sequencing actions in interaction, para- and nonverbal aspects of talk), and (b) constructing particular versions of gendered self, other, and gender relations. People's re-production of gendered discourse constitutes people as members of (binary) gender categories ("men" and "women"), as possessing certain gendered predispositions or attributes, and as relating to each other in particular ways (e.g., women being different from, or inferior to, men, men and women complementing each other as nurturers and providers).

Gendered discourse is predominantly sexist; it draws upon gender stereotypes and prejudices, or oversimplified and negative portrayals of members of certain groups, particularly women. Sexist portrayals of women help justify and maintain gender inequalities and oppression (Ridgeway, 2011; Risman, 2012). Discourse, from this perspective, is not a means of transferring or communicating information about who people are as gendered beings but a way to create and maintain gendered hierarchies. Let us illustrate the link between discourse and power. I (OS) recently showed a training video to students in a couple therapy course. Although explicitly discussing the constraining effects of gender norms at some point during the session, the therapist repeatedly referred to a female-identifying client as "your lady" when talking to her male-identifying partner. What may seem merely to be a descriptive reference to her as his wife may also be considered a way to sustain gendered and sexual hierarchies (e.g., women as commodities or possessions of men, mono- and heterosexual relationships as privileged). Adding another layer to this analysis, the interaction on the recording is between two clients of color and a white therapist. For some clients of color, expressions like this one may introduce 
a distinct set of race-related associations about certain groups of people being seen and treated as properties of other people. It can also be seen as a way to sustain hierarchies among different groups of women. The term "lady" can advance constructions of femininity privileged in certain contexts, which can be used to "other" women (e.g., working class, non-white, disabled, queer) whose embodiments depart from "lady-like" normative conduct and appearance. By signaling class and race-related respectability, use of the term "lady" re-produces an implicit binary between respectable and good versus disreputable, improper, and bad women. These points are not to suggest that the work of the therapist on the recording lacks diversity sensitivity but to highlight how all of us may become implicated in the re-production of dominant notions of gender and relations of power, unless we pay attention to how we use language.

\section{The Study of Gendered Discourse in Family Therapy}

Family therapy has been stuck in binary (e.g., male/female, same sex/opposite sex) notions of gender and sexuality (Giammattei, 2015; Waldegrave, 2009), despite the professional expectation that therapists offer diversity-sensitive and antioppressive services (American Association for Marriage and Family Therapy, 2015). Many family therapists struggle to recognize sexism and other -isms in their practice and in families' interactions (Giammattei, 2015; Knudson-Martin, 2013). In part, this is because there is little guidance in the field for how to address gender and power (Knudson-Martin, 2013).

Much of the recent work on gender and gendered power in family therapy is conceptual (Dickerson, 2013; Falicov, 2010; Giammattei, 2015; Knudson-Martin, 2013; Lev, 2010). For example, Falicov (2010) discussed 
constructions of Latino heterosexual masculinity. She encouraged therapists to deconstruct dominant gendered discourses and explore alternative narratives that support diverse masculinities. In discussing the "how" of this deconstructive work, Falicov suggested to "respectfully inquire about what is authentic or heartfelt as opposed to what is mere performance in the displays of invincible masculinity" (p. 322). Similarly, Dickerson (2013) offered a case study illustrating a narrative, poststructural approach to addressing gender and gendered power in therapy involving heterosexual couples. A transcript of a recalled therapeutic interaction illustrates how a therapist can notice signs of patriarchy in clients' words (e.g., framing "sadness" and "depression" experienced by a client who is not able to bear biological children as a response to cultural pressure placed on women to become mothers). Lev (2010) presented a case study of a lesbian couple with a 5-year-old child showing how LGBTQ families draw on and subvert dominant cultural constructs of gender in their intimate relations and parenting, specifically how LGBTQ parents may experience cultural pressure to produce gender-normative and heterosexual children.

Some empirical work has also been conducted. Family relations scholars have quantitatively approached the study of (sexist) gender role attitudes, exploring their link to other constructs, such as marital satisfaction, role overload, and housework (Helms, Walls, Crouter, \& McHale, 2010; Shapiro, 2014; Toomey, Updegraff, Umaña-Taylor, \& Jahromi, 2015). Most family therapy scholarship on gender and genderbased power is qualitative and involves analyses of interview data involving therapists (Goodwin, Kaestle, \& Piercy, 2013; Keeling \& Piercy, 2007; Knudson-Martin et al., 2015; Parker, 2009) or family members (Cowdery et 
al., 2009; Knudson-Martin \& Mahoney, 2009; Maciel et al., 2009; Reynolds and Knudson-Martin, 2015), with some studies exploring recorded interactions between therapists and clients (Ward \& Knudson-Martin, 2012).

For instance, Knudson-Martin et al. (2015) analyzed their own therapy practice to identify competencies necessary for addressing gender and power. They uncovered and illustrated multiple competencies using recalled examples from their practice. One of the competencies described is attention to how cultural discourse is enacted in therapy, which involves "listen[ing] for context," "expand[ing] conversation regarding cultural discourse," and "explor[ing] personal meanings around cultural discourses" (p. 208). Expanding conversation regarding cultural discourse involves recognizing and exploring gendered discourses (e.g., stereotypical portrayals of women as dependent) and examining alternative constructions of gender. Keeling and Piercy (2007) conducted an online survey with 16 therapists across 15 countries to investigate how therapists address gender and power in therapy. They used grounded theory's constant comparison method to examine participants' responses. One of the categories "addressing gender and power" offers recommendations about when and how to explore issues of gender and power in therapy. For example, therapists are advised to discuss gender and power in respectful ways, challenge gender and inequality only when the alliance is strong, use nonthreatening approaches, and promote reconstruction of meaning.

Goodwin et al. (2013) used grounded theory to analyze 10 feministidentified therapists' accounts, generated through interviews, of how they have developed as feminist therapists and how they have resisted and 
colluded with oppression. The authors suggested, among other conclusions, that "drawing attention [to gender and power] can be done through provoking conversation, recognizing the social prescription of values, exposing relationships, examining prevalent discourse, and critiquing social norms" (p. 244). Participants discussed collusion with oppression as a passive act involving "going along with someone even if I knew better" (p. 248). Similarly, Parker (2009) conducted interviews with "expert" family therapists inquiring about how they address gender and gendered power in sessions and analyzed them using a grounded theory approach. She identified six practices, which included the assessment of power and privilege (e.g., how partners negotiate childcare), cultural genogram, and activities or practices aimed at raising social awareness (e.g., a film). Some have studied gendered discourse by examining recorded therapy sessions. Ward and Knudson-Martin (2012) examined couple therapy transcripts, using a grounded theory approach, and identified five kinds of therapist actions that reinforce gendered power. These include, among others, discounting the person in the one-down position, allowing the one-up person to define the conversation, and speaking as though the relationship was equal.

\section{Constructionist Critique of the Prior Constructionist Gender Scholarship}

This body of work is important, as it helps highlight areas of focus in supporting families toward gender equality and better preparing therapists for diversity-oriented and social justice work. It is also limited in a number of ways. We see three main difficulties with current approaches to the study of gender and power in family therapy: (a) the use of premises and methods 
inconsistent with a constructionist, discursive lens, (b) insufficient precision in constructionist formulations of gender and oppression, and (c) the nearly exclusive reliance on methods of inquiry that are limited in clarifying how gender is constituted through discourse.

The first difficulty arises from a lack of consistency in theoretical premises, particularly concerning the constructed nature of subjectivity and power. There seems to be a disconnect between the theory of gender that family therapy scholars adopt and their analyses of the "social construction of gender." Researchers paradoxically seek understandings of gendered discourse "outside" and "beyond" discourse. Participants' accounts are implicitly treated as a pathway to their experiences or perspectives on "what really happens" in family relationships and therapy (Potter \& Hepburn, 2005). Language, from this perspective, is seen as representing stereotypical notions of gender (which are viewed as already "there" in couple relationships or partners' minds) rather than as constituting such notions. The field's nearly exclusive reliance on grounded theory methodology and associated content-focused approaches is a doubleedged sword: It helps identify general markers of inequality and sexism in discourse, while simultaneously obscuring how discourse itself produces certain versions of gender and social relations.

Adding to this, a second critique concerns the requirement to elaborate, both theoretically and analytically, on how exactly the social construction of gender and gendered power take place. Researchers have developed and applied a wide variety of social constructionisms across disciplines and in the study of gender (see Holstein \& Gubrium, 2008; Lock \& Strong, 2010; Speer \& Stokoe, 2011). These include ethnomethodology, 
discursive psychology, positioning theory, performativity theory, and other postmodern and poststructural perspectives. Family therapy has yet to take advantage of this diverse body of literature and to challenge researchers' and therapists' propensity to advance a unified or unspecified "social constructionist" perspective on gender. Many studies do not go beyond merely asserting that gender is constructed. The field can benefit from greater theoretical transparency in the study of gender construction, which could help clarify which theoretical commitments inform specific studies and ensure consistency between theoretical and research frameworks.

The third critique calls for a greater specificity and nuance in the study of the social construction of gender. Prior research highlights that gender and gender-based oppression are constructed through social interaction but does not clarify how, specifically, this is done. It helps identify general components, processes, assumptions, and patterns of action involved in the social construction of gender and power within families and in therapy, but overlooks how discourse-envisioned as fluid, joint, variable, and context bound-is a key part of this process. The use of hypothetical and recalled exchanges between therapists and clients helpfully shows how gendered discourse may enter therapy, yet these only offer a "broad stroke" and, to some degree, imaginary portrayal of language use (Kitzinger, 2009; Speer, 2005). This leaves therapists uncertain about how gendered discourse is constituted in "real life," both within specific couple or therapeutic interactions and across interactional contexts. Lacking are accounts that demonstrate the evolution and fluidity of gendered meaning and how entitlements, roles, and obligations are not 
stable attributes of people but are discursively or interactionally constituted and negotiated (e.g., contested, undermined, endorsed, or extended).

Furthermore, existing studies help identify gendered norms (egalitarian and traditional) couples endorse, yet largely overlook the multiplicity of meaning, that is, how the same couple, partner, or speaker's utterance may promote multiple, even contradictory, gender understandings and expectations (e.g., she is free to do what she wants, but I hope she can see how great she is with kids and how miserable our children will be if she decides to work). Recalled interactions are also limited in "capturing" the contextual specificity and variability of language use or how meanings concerning gender are produced in situ and what local functions such constructions or understandings serve. Speer (2005) noted that the same utterance may have sexist or egalitarian meaning depending on the context of its use, and that an approach that seeks to generate a generic list of sexist and non-sexist utterances or responses may be misleading. She illustrated this point with examples of how derogatory terms, such as "dyke" or "queer," may be reclaimed by LGBTQ individuals and used to emancipatory ends (Speer \& Potter, 2000) or how utterances that seem merely descriptive or those that explicitly claim to be nonsexist (e.g., I am not sexist but...) may subtly advance prejudiced views toward women (e.g., Stokoe \& Smithson, 2002).

Finally, content-focused analyses are limited in addressing subtle operations of gender and power. Given that participants themselves may not always recognize power (Knudson-Martin, 2013), analyses may need to move beyond what participants say about their identities and relationships to how they re-produce and challenge conventional and binary gender 
through their conduct and interactions, including interactions that do not contain explicit references to gender (Kitzinger \& Wilkinson, 1997).

Discourse analytic methods (e.g., conversation analysis, critical discourse analysis, discursive psychology, membership categorization analysis) can address the gap and difficulties discussed above. Although there is a burgeoning body of discursive empirical work on gender/diversity outside of family therapy, including in the study of the family (Adjei, 2016; Dalgaard, 2016), family therapy has trailed behind in using discursive methods in general (Tseliou, 2013) and in examining gender/diversity in particular. None of the existing discursive analyses of family therapy (Lawless, Gale, \& Bacigalupe, 2001; Moore \& Seu, 2010; O'Reilly, 2014; Singh, 2009) directly address the construction of gender/diversity and power relations. For example, Lawless et al. (2001) investigated how talk about race and ethnicity was built and negotiated in supervision meetings, leaving the discursive production of client and supervisor/supervisee race and ethnicity unexplored. Singh (2009) used discourse analysis to investigate constructions of the family in therapy involving white British and South-Asian therapists and families, similarly bypassing the construction of difference in therapeutic conversations between white therapists and racialized clients. Even studies oriented toward unpacking the operation of "culture" or sexuality in therapist-client discourse (Finn, Tunariu, \& Lee, 2012; Lee et al., 2017; Pakes \& Roy-Chowdhury, 2007) do not tap into the specific ways in which discourse constitutes social differences and power relations. The only exception we were able to locate is a discourse analytic analysis of how, or through which cultural discourses, white systemic therapists constructed "whiteness" in focus group discussions (Walls \& 
Singh, 2014). Particularly missing are micro-oriented discursive analyses of how people are categorized in terms of race, gender, or sexuality and how "cultural differences" are oriented to and accomplished by the participants through the development of their interaction.

In the next section, we present discursive analyses of gender and gender-based inequality published outside of family therapy. By discussing selected discursive methods, we hope to illustrate how attending to discourse enriches our understanding of gender, power, and difference. Our illustration inevitably simplifies the complexities of discursive approaches. Each research tradition is best viewed not as a singular unified methodology, but as a collection of methods, foci, and premises. The scope of this study also does not permit the discussion of debates and tensions within discursive inquiry. Our analysis reflects our reading of these examples. Inevitably, we will have interpreted some claims in ways with which others, including the researchers themselves, might disagree.

\section{Discourse Analysis}

Discourse analysis comprises a wide range of approaches to examining text and talk (Sidnell \& Stivers, 2013; Tileagă \& Stokoe, 2016; Wodak \& Meyer, 2016). Its focus is on language in use or how people employ language in specific contexts. Discursive analysts adopt a dual approach to the study of discourse, focusing on both the constructed nature of discourse or how it is put together using a range of discursive practices (e.g., lexical, prosodic, syntactic) and the constructive nature of discourse or how it produces different versions or representations of the world (Potter \& Hepburn, 2008). The underlying premise is that people use language to 
construct social reality (e.g., identity, relations, obligations, entitlements) and to perform social action, such as invite, greet, or persuade.

\section{Critical Discourse Analysis}

Critical discourse analysis [CDA] is a multidisciplinary research tradition rooted in Marxism, critical theory, poststructuralism, and semiotics. It was developed in the early 1990s in Amsterdam by a group of critical scholars interested in the analysis of discourse (e.g., Norman Fairclough, Ruth Wodak, Teun van Dijk, Theo van Leeuwan, Gunther Kress). There are various approaches to CDA (see Wodak \& Meyer, 2016, for an overview), but all share a common intention to expose power relations and ideologies that underlie people's actions and consciousness. CDA critically examines the relatively stabilized forms of social activity that bring about social order or organization, focusing on social practices that legitimize control and inequality in a society (Fairclough, 2013). Power is often institutionalized, and in the hierarchy of power there are elite groups that consist of individuals who play special roles in decision-making, control, and planning (van Dijk, 2001). CDA undermines power practices by revealing them as contestable, while exploring and facilitating practices of counterpower (Fairclough, 2013). CDA scholars position themselves critically in relation to the material they analyze and assume that social change will take place through critical analysis and reflection. Critical discourse analysts tend to focus on how hegemonic cultural values position people to act and think in particular ways (Wetherell, 1998). They do not start from text and talk (as conversation analysts do, see below), but from prominent sociopolitical issues and dynamics affecting people's consciousness and actions (Fairclough, 2013). 
Sunderland (2006) used CDA to examine how fathers are represented in magazines about parenting. On the surface, magazines promoted gender-neutral language. However, an in-depth critical analysis of text and images revealed many instances in which mothers were centered. In advice-giving articles, the plural "you" pronoun meant to address a parent (of any gender) was used to refer to a feminine parent (e.g., You've undoubtedly been smothering your baby and saying things like 'Give mommy a kiss'..., p. 512). When fathers were referenced, they were constituted as secondary caregivers. Examples include: Massage may help new fathers bond with their babies, Kids win when dads stay in touch, If you have a 4, 5, and 8-year-old, the 8-year-old can stay up a little longer and hang out with Dad while Mom is bathing the younger ones (pp. 512-513). There was also a paucity of visual representations of masculineembodied caregivers. Women were treated as primary recipients of advice and were assumed to inhabit female-coded bodies (to have breasts, to have given birth) and hence to be cisgendered. This was particularly noticeable in advice about breastfeeding (e.g., Breastfeed if you can, p. 519). Gendered stereotypes and normative heterosexuality were reinforced through professionals or "experts" on parenting offering advice (e.g., I sometimes wish parents would ask themselves, 'Would my mother have called the doctor about this?' p. 520). A more content-focused analysis might have missed the subtle ways in which the discourse itself is involved in the construction of gender and power in these examples; importantly, they also draw our attention to the interactional accomplishment of normative gender categories (masculine, feminine) and sexed bodies (male, female) and erasure of trans identifications through discourse. 
Critical discourse analysis can help scholars clarify how prevailing cultural ideas concerning gender, family, and so forth are reproduced and reinforced (and challenged and modified) through people's use of language. Most other qualitative and quantitative methodologies tend to focus on the content of what people say about gender and gender-based relations and overlook how normative gender (people's situated uptake of gendered norms and discourses) may position people to act and relate in certain gendered ways, often outside of their conscious awareness of power dynamics. CDA can help scholars and practitioners not only recognize how gender constitutes people into "male" and "female" subjects who are hierarchically related but also reconcile contradictory positions, such as the same speaker simultaneously enacting and challenging binary or normative gender.

\section{Conversation Analysis}

Conversation analysis (CA; Sacks, 1992; Sidnell, 2010; Sidnell \& Stivers, 2013) is one of the most prominent approaches to the study of social interaction across disciplines. It is rooted in ethnomethodological concern with members' methods for organizing their relations and interaction, among other traditions (Maynard, 2013). CA's main objective is to identify structures underlying social interaction, that is, members' mutually relied upon methods and practices used to order interaction. CA treats and studies people's everyday use of language as a pervasively orderly phenomenon. Such order is evident, for instance, in how people exchange speaking turns, how they initiate or exit interaction, or how they repair misunderstanding. CA's key distinctiveness lies in its concern with the organization of talk not from an external viewpoint but from the 
perspective of the participants in interaction. That is, participants display to one another their understanding of "what is going on" in interaction, for example, what the prior turn is about (e.g., seeking information, inviting, accusing; Sacks, 1992; Schegloff \& Sacks, 1973). Understanding is commonly achieved and displayed through participants sequentially structuring their interaction using paired actions (e.g., greeting-greeting, accusation-account, question-answer; Schegloff \& Sacks, 1973). Conversation analysts study naturally occurring interactions, recorded and transcribed in detail, including pauses, intonation, and pitch (Sidnell, 2010).

Conversation analysts conceive of culture, including gendered norms, as both the product and project of participants' situated actions and inferences. While critical discourse analysts tend to assume a priori that interactions between people of "opposite" genders are characterized by particular dynamics (e.g., unequal division of labor), CA practitioners tend to demonstrate how participants orient themselves to the relevance of gender (Schegloff, 1997). Conversation analysts have criticized critical discourse analysts for advocating social determinism, which positions the sociocultural context as external forces constraining local action and interaction from the "outside" (Schegloff, 1997). In contrast, CA practitioners treat gender and other categories of identity as issues to be referenced, evoked, and managed in the interaction (Schegloff, 1997). In turn, others have critiqued CA for being limited in the study of power due to its disregard of wider ideological meaning of talk unless participants themselves attend to gender ideology, such as gender conventions and norms (Weatherall, 2016). 
Consider the following exemplar (taken from Heritage \& Sefi, 1992) as a demonstration of how CA practitioners address gender and gendered power. The example shows a portion of an interaction between a health visitor (HV; a nurse) and first-time mother and father. In the United Kingdom, HVs assist parents in the care of babies by offering education and guidance (see Table 1 for the CA transcription notation).

$1 \quad \mathrm{HV}: \quad$ He's enjoying that isn't he

$2 \rightarrow \quad F: \quad{ }^{\circ}$ Yes, he certainly is $=^{\circ}$

$3 \rightarrow \quad M: \quad=H e$ 's not hungry 'cuz $(h) h e ' s$ ju(h)st $(h)$ had 'iz bo:ttle $\cdot$ hhh

4 $(.5)$

$5 \quad$ HV: You're feeding him on (.) Cow and Gate Premium (p. 367)

The remark in line 1 presumably reflects the HV's observation that the baby is chewing or sucking on something. While the father simply agrees with the HV's observation, the mother's response appears defensive. She orients to both the HV's role as an observer or evaluator of childcare and to her own (gendered) role and responsibility to provide adequate care. The parents' different responses may reflect the traditional gender-based division of labor within a family in which the mother is responsible for child rearing. Even if the father had been responsible for the feeding of the child, it is the mother who assumes a criticism has been made by the HV and provides an unsolicited defense. The example shows differential orientations: One partner orients to parental obligations, the 
other does not. "Obligations" here are the participants' (rather than the analysts') concern.

\section{Table 1. Conversation Analytic Transcription Conventions}

Silence represented in tenths of a second

(.)

An untimed short pause There is no discernible pause between the end of a speaker's utterance and the beginning of the next utterance

( ) Material in parentheses is inaudible

(( )) Comments of the researcher

:

Under Words that were uttered with added emphasis

CAPITAL Words were uttered louder than the surrounding talk

hhh Hearable aspiration (laughter, breathing); if in parentheses (hhh) - appears within words

.hhh Inhalation of breath

? $\quad$ A rising inflection

. A stopping fall in tone

$\circ$ Talk between ${ }^{\circ}{ }^{\circ}$ is quieter than surrounding talk

$>\quad$ Talk between $><$ is quicker than surrounding talk

[ ] Overlap of talk

$\uparrow \quad$ Rises in pitch

Note: Adapted from "Conversation analysis: An introduction" by Sidnell (2010).

Another CA example we present is taken from Schegloff (1997). The interaction involves two couples: Shane and Vivian and Michael and Nancy. 


\begin{tabular}{|c|c|c|c|}
\hline 1 & Shane: & & [hehh huh hhhh Most wishful thinkin \\
\hline 2 & & $\rightarrow$ & hey hand me some a 'dat funkin budder willyou? \\
\hline 3 & & & $(0.8)$ \\
\hline 4 & Shane: & & ${ }^{\circ} \mathrm{Oh}:: y e a{ }^{\circ \circ}$ \\
\hline 5 & & & $(1.1)$ \\
\hline 6 & Nancy: & $\rightarrow$ & C'n I have some t[oo \\
\hline 7 & Michael: & & [mm-hm-[hm: \\
\hline 8 & Nancy: & & {$\left[\mathrm{hm}-\mathrm{hm}-{ }^{\wedge} \mathrm{h}\left[\quad\left[{ }^{\wedge}\right.\right.\right.$ he-ha- $]$ ha hehh $]$} \\
\hline 9 & Vivian: & $\rightarrow$ & [Ye[h [I wa]nt ]sometoo.] \\
\hline 10 & Shane: & & {$[N[\mathrm{no}:].[($ )- } \\
\hline 11 & Shane: & & No. \\
\hline 12 & & & $(0.2)$ \\
\hline 13 & Shane & $\rightarrow$ & Ladies la:st \\
\hline
\end{tabular}


Shane requests butter located on the table beside Michael (line 2). In describing the verbal aspect of the interaction, Schegloff mentions that Michael observably makes sense of Shane's utterance as a request addressed to him as evident in him producing a compliant response (handing Shane butter). He begins handing it even before Shane completes his request (at the word "some"). Vivian and Nancy issue the same request to Shane to hand them some butter (lines 6 and 9). In responding, Shane rejects their request (lines 10 and 11) and continues to serve butter to himself, providing an account or explanation for the rejection (line 13).

Shane treats Vivian and Nancy's gender as a relevant matter. He reformulates the gendered cultural rule "ladies first" into "ladies last." The reformulated rule is more in line with his actual conduct. "Ladies last" is offered as an account of Shane continuing to serve butter to himself. "Ladies first" is a gender norm or expectation reflective of the broader cultural discourse or notion that women should be cherished and protected (by men). CA analyses challenge the notion that gender norms show up in discourse in a uniform way and illustrate how speakers may reference or evoke categories (and associated predicates, activities, obligations, etc.) variably and resourcefully. In this excerpt, Shane references and modifies the norm "ladies first" to (ironically) explain his rejection of Vivian and Nancy's requests. A CDA researcher might construe Shane's actions as an expression of his gender and conclude that Shane's "ladies last" may be a way of entitling the male self. CDA scholars use gender as their interpretive resource for making sense of participants' conduct. "Shane," to a CDA scholar, marks male gender and his continuing to serve butter to himself is 
an example and enactment of his male entitlement. In contrast, a conversation analyst would attend to how participants themselves use gender (e.g., gender binaries and conventions) as a resource in doing whatever they are doing, such as asking, requesting, declining, or justifying. CA is a unique approach to the study of gender as a local coconstruction. CA practitioners approach and examine gender discourse as a "tool" or resource for getting things done in interaction, rather than as an expression of a stable and internal gendered (e.g., feminine) nature. They examine how participants variably constitute gender identities, responsibilities, obligations, rights, entitlements, expectations, and alike and the interactional effects of constituted gender.

\section{Discursive Psychology}

Discursive psychology [DP] was developed in the late 1980s by the members of the Discourse and Rhetoric Group (e.g., Charles Antaki, Jonathan Potter, Derek Edwards, Margaret Wetherell, Michael Billig) at Loughborough University in the United Kingdom (Edwards \& Potter, 1992; Tileagă \& Stokoe, 2016). While typically using the same analytical procedures as CA, DP distinguishes itself by its focus: psychological matters including emotion, personality, cognition, memory, attribution, attitude, etc. Rather than treating language as an expression of real, underlying psychological processes, discursive psychologists examine mental states as discursive accomplishments: matters that speakers orient to in, and accomplish with, their talk. Discursive psychologists focus on the rhetorical organization of talk (e.g., How is a specific description of an event or person accomplished as a factual or objective? How is an account constructed to undermine alternative explanations? How, for instance, are 
emotions or attributions of causes or characteristics constituted and for what rhetorical purposes?).

Conventional approaches are not well equipped to account for variability in participants' reports. These approaches are limited in explaining and reconciling seemingly paradoxical or contradictory conclusions; for example, couples might simultaneously aspire to be egalitarian and endorse traditional gender roles. Similarly, speakers may express both sexist and feminist attitudes. Part of the issue is that participants' descriptions of their actions and relationships are abstracted from concrete settings or situations in which these descriptions were produced. In contrast, DP scholars presume account variability and contextual specificity. They examine how participants employ account variability for specific purposes (e.g., to express a sexist opinion while appearing nonsexist) (Speer \& Potter, 2000; Stokoe \& Smithson, 2001). DP can shed light on how prejudices like sexism, heterosexism, and racism, among others, are produced in interaction. DP practitioners challenge conventional notions of sexist attitudes or negative evaluations of members of certain groups as stable and cognitive matters. Instead, they stress that sexist and heterosexist statements are produced in situ-interpreted as problematic or immoral, assembled as factual rather than reflective of a personal viewpoint, used for different social purposes.

Speer and Potter (2000) examined heterosexist talk from a variety of sources and described how participants oriented to sexuality and heterosexism in their talk and what such orientations helped them accomplish in specific contexts. In the next excerpt, Ben, a self-identified 
heterosexual man in his mid-20s, responds to the interviewer's (Sue) question about his experience of going to a gay club:

$1 \quad$ S: Did you enjoy going to the gay club?

2 B: Yeah I $\uparrow$ did. I had a bloody good ttime.

3 S: Was it a different kind of experience from a:

$4 \quad$ (.) () the pubs you're used to?

5 B: $\uparrow$ Erm (2.0) yeah it was a different experience

6 but (1.0) it didn't bother me (0.4) you know.

7 The difference was (.) er:, (1.0) knowing the

8 fact that the: (.) №, it wasn't knowing the

9 fact. (0.4) > You know < it wouldn't have

10 bothered me if I didn't know.(0.4) The

11 difference was they're very $(0.4)^{\circ}{ }^{\circ} \mathrm{erm}^{\circ}$

12 (2.0) well, the fact that you get men (.)

13 going past you and saying "excuse me darling"

14 (.) instead of (.) "excuse me mate" or (0.6)

15 "coming through" or what- you know, they're

$16 \quad(0.8)$ ob(h)viously more feminine a lot of

17 them. (1.0) Or er (.) you know, you get men

18 coming onto you sometimes. (0.8) But it

19 doesn't bother me. (.) You know, l'll be

20 straight and honest with anyone ${ }^{\circ}$ and say ${ }^{\circ}$

21 "I'm sorry I'm not interested." (pp. 549-550) 
Ben is faced with two challenges prompted by Sue's question in line 1: to not appear prejudiced against gay people and, if he endorses that he enjoyed going to a gay club, to not indicate that he himself is gay. Ben agrees that he enjoyed his experience and upgrades his evaluation ( I had a bloody good time), which could be a strategy to counter any notion that he is prejudiced against gay people. In his extended answer to Sue's follow-up question, Ben recurrently asserts that the experience of going to a gay club did not "bother" him (lines 6, 10, 19). According to Speer and Potter, Ben's denials are issued in response to potential counterclaims that he may be "bothered" by the experience. Ben simultaneously orients to a possibility of others interpreting his enjoyment and lack of bother as him being a homosexual, as evident in his efforts to counter the idea that he is gay $(\mathrm{I} m$ sorry I'm not interested, line 21). In reporting his speech in hypothetical interactions with gay men, he is also polite and respectful, which works to display his lack of prejudice. The researchers highlight how sexuality and heterosexism are not only their concerns but also situated concerns of participants. Ben makes his sexuality relevant and explicit to Sue whose reference to enjoyment of a gay club evokes cultural notions that someone who enjoys going to a gay club is likely a gay or that if someone does not like going to a gay club, they are possibly prejudiced against gay people. Ben orients to these possible hearings of his response to Sue's question and resourcefully manages issues of heterosexism and his own sexuality.

\section{Discussion}

Family therapists increasingly see discourse as pivotal to the production of gendered subjectivities and relations (Dickerson, 2013; HareMustin, 1994; Keeling et al., 2010; Maciel et al., 2009). In this article, we 
have argued that the emerging discursive conceptions of gender and gendered power have not been accompanied by applications and developments of discursive methods of analysis in research. We proposed that discursive research can be a valuable tool for examining gender and gendered power. Clearly, there are many legitimate and potentially valuable approaches to the study of gender as socially constituted. As we have suggested, a discursive approach offers a range of distinct advantages over currently employed alternatives.

Firstly, and arguably most importantly, the study of gender as discourse helps preserve, grasp, and nuance the complexity and dynamism potentially overlooked when alternative approaches are employed that treat gender and other social categories as demographic variables or as fixed categories. Discursive analysis goes beyond the study of gendered identities and relations as uniform, binary, and categorical (as either equal or unequal, done or undone, hegemonic or subversive, masculine or feminine, as rooted exclusively in male or female bodies). Rather than presuming stable gender or power arrangements, the focus is on how selves are variably and multiply constituted as gendered and relations as un/equal. Taking seriously the social constructionist premise concerning the constructed nature of gender means paying close attention to discourse or the development and negotiation of meaning in specific contexts. If we assume that gendered disparities are not conditions reflective of real biological or psychological differences (e.g., women are better suited for domestic tasks) but a means to constitute and maintain inequalities, it is important to grasp how gender differences are assembled as real or natural and how they are put to work and to what ends. By leaving undisturbed the 
social construction of gender and power, we may inadvertently become complicit in the dynamics of power we seek to challenge.

A discursive lens envisions participants' concerns as context-shaped or situated. By "situated" we mean formulated in nuanced, variable ways and adjusted in light of specific aims and circumstances. This approach resists the presupposition of inherent in/equality in a family relationship and starts from discourse by examining how specific meanings of family relations and family members' identities and obligations are worked up and negotiated in specific contexts. Discursive inquiry can supply empirical evidence for the poststructural premise concerning modern forms of power in the West: that power is socially distributed rather than centralized and that it is constructive of, rather than deployed by, subjects (Foucault, 1982). An analysis that treats power as socially distributed and produced rather than fixed and residing in specific groups or people can also complicate a seemingly straightforward link between social location and power by highlighting that white, male, heterosexual, etc. bodies can act in ways that destabilize relations of power, while individuals distinguished as socially disadvantaged can participate in their own subjugation and reinforce social disparities. Furthermore, detailed analyses of discourse can reveal that the same speaker's contributions to discourse can both reinforce power arrangements and, potentially simultaneously, challenge them or can advance some relations of power while undermining other relations.

\section{Implications for Therapists}

Discursive knowledge concerning gender can be highly relevant to family therapists. In highlighting the importance of therapists attending to and challenging dominant constructions of sexuality and gender, Hudak 
and Giamattei (2010) remarked, "by not questioning current language, false dichotomies, and essentialist views, family therapy colludes with the discourses that, at worse, pathologize the natural variability of human nature, and, at a minimum, render variations invisible" (p. 7). Applying discursive methods can help therapists move beyond universal, binary, and culturally dominant accounts of gender and toward understanding gender diversity in its variability and complexity. It can help therapists recognize not only when and how structural forces enter family life and therapy (e.g., when family members or therapists begin to draw on stereotypical or binary notions of gender) but also efforts already taken within families to challenge gender assumptions and norms and transform sociopolitical arrangements. We appreciate the potential of discursive inquiry to offer critical readings depicting how the regulation and normalization of people into groups (e.g., able-bodied, white, heterosexual) works in mundane and subtle ways. What we appreciate even more is its focus on the microdetails of talk-its capacity to distinctly take apart and make visible the processes and practices involved in the construction of gendered and other differenceinflected subjectivities and relations. Discursive inquiry helps identify discursive resources and practices employed in the doing of gender and sensitize therapists to how their (and families') use of language reproduces and challenges normative gender and power.

In a recent discursive study (Sutherland et al., 2017), we showed how partners in intimate relationships evoked sexist notions (e.g., women are "natural" caregivers, men are not as relationally oriented as women) for specific social and rhetorical purposes. For example, one participant reported speech of other men (all the guys that I've talked to say the same 
thing 'what can you do, there is nothing that you can really do as a guy for the first couple of months') and produced complete unanimity among men (note the extreme case formulation "all" in all the guys). These practices arguably helped bolster the facticity of his claim that fathers' involvement when a child is newborn is unnecessary and present such a claim as a reflection of a consensual male viewpoint rather than as motivated by personal interests, namely, to be excused from childcare. Having read the analysis, therapists may "hold on" to extreme formulations and reported speech as potential ways to strengthen or undermine sexist notions of parenting. Recognizing sexism in mundane seemingly apolitical discussions, therapists might also invite partners to interrogate the symbolic and material effects of their claims and exchanges as well as explore their own contributions to sexist discourse.

\section{Implications for Researchers}

Discourse analysis is a theoretically compatible alternative to many methods of inquiry currently used in the field. Discursive research could help researchers to more fully and rigorously answer key questions that concern therapists, such as: How do clients and therapists construct and use gender, racial, sexual, and other identities in talk? How do they perform and transgress normative gender? How do participants in therapy enact multiple, contradictory gender identities in talk? How are essentialist and binary constructions of gender (e.g., men/women, men are .../women are...) constituted in therapy? How do people categorize themselves and others (e.g., as members of certain social groups) and what social actions do different ways of categorizing accomplish? How are sexism, heterosexism, and other types of prejudice and stereotyping accomplished 
in talk and text? How do feminist premises and aims translate into therapy practice and how do clients respond to therapists' social justice initiatives? How can therapists address power and not "lose" the clients, particularly family members who may be invested in maintaining the status quo? Specific recommendations for family therapy scholars include the following: examine sexist discourse as coconstructed rather than as conveyed or enacted by men in relation to women; transcribe and analyze all speakers' contributions to discourse; study "real-life" instances of discourse; examine language use in context; analyze prolonged stretches of discourse; examine the microdetails of gendered discourse; look "beyond" what people say about their relationships and identities to how discourse constitutes conventional gender and hierarchies; and examine not only explicitly gendered talk but also any aspect of interaction.

\section{Conclusions}

Scholarly innovations and developments in discursive scholarship in family therapy are salient given recent social changes. These include an upward trend in ethnocultural diversity in Canada and the United States and growing recognition and acceptance of diversity and complexity of family form and organization (e.g., cohabitating, single-parent, interracial, polyamorous, transgender, and gender nonconforming individuals and families; e.g., Blumer, Ansaram \& Watson, 2013; Hudak \& Giamattei, 2010; Leslie \& Morton, 2001). These changes speak to the importance of family scholars and therapists evaluating the extent to which their work attends to issues of diversity and power. Given increasing interest in social constructionist formulations of gender, and changes in contemporary family structures and relations, it seems important to equip family therapy 
scholars and practitioners with research frameworks that can help address many unanswered questions about the ordinary ways in which gender and gendered power and privilege operate and are constituted in daily family interactions.

\section{References}

Adjei, S. B. (2016). Masculinity and spousal violence: Discursive accounts of husbands who abuse their wives in Ghana. Journal of Family Violence, 31(4), 411-422.

American Association for Marriage and Family Therapy (2015). American Association for Marriage and Family Therapy Code of Ethics. Alexandria, VA: Author. Retrieved from http://www.aamft.org/imis15/content/legal_ethics/code_of_ethics.aspx

Anderson, H. (2012). Collaborative relationships and dialogic conversations: Ideas for a relationally responsive practice. Family Process, 51(1), 8-24.

Anderson, H. D. (1997). Conversation, language, and possibilities: A postmodern approach to therapy. New York: Basic Books.

Baker, P. (2016). Gendered discourses. In P. Baker \& J. Elbert (Eds.), Triangulating methodological approaches in corpus linguistic research (pp. 138-150). New York: Routledge.

Blumer, M. L. C., Ansara, Y. G., \& Watson, C. M. (2013). Cisgenderism in family therapy: How everyday clinical practices can delegitimize people's gender self-designations. Journal of Family Psychotherapy, 24(4), 267-285. 
Borcsa, M, \& P. Rober (Eds.) (2016). Research perspectives in couple therapy. Discursive qualitative methods. New York: Springer.

Combs, G., \& Freedman, J. (2016). Narrative therapy's relational understanding of identity. Family Process, 55(2), 211-224.

Cowdery, R. S., Scarborough, N., Knudson-Martin, C., Seshadri, G., Lewis, M. E., \& Mahoney, A. R. (2009). Gendered power in cultural contexts: Part II. Middle class African American heterosexual couples with young children. Family Process, 48(1), 25-39.

Dalgaard, N. T. (2016). The impact of Islam and the public and political portrayals of Islam on child-rearing practices-Discursive analyses of parental accounts among Muslims living in Denmark. Culture and Psychology, 22(1), 65-79.

De Haene, L. (2010). Beyond division: Convergences between postmodern qualitative research and family therapy. Journal of Marital and Family Therapy, 36(1), 1-12.

Dickerson, V. C. (2013). Patriarchy, power, and privilege: A narrative poststructural view of work with couples. Family Process, 52, 102 114.

Edwards, D., \& Potter, J. (1992). Discursive psychology. London, UK: Sage.

Fairclough, N. (2013). Critical discourse analysis: The critical study of language (2nd ed.). New York: Routledge.

Falicov, C. J. (2010). Changing constructions of machismo for Latino men in therapy: "The devil never sleeps". Family Process, 49, 309-329. 
Finn, M. D., Tunariu, A. D., \& Lee, K. C. (2012). A critical analysis of affirmative therapeutic engagements with consensual nonmonogamy. Sexual and Relationship Therapy, 27(3), 205-216.

Foucault, M. (1981). The order of discourse. In R. Young (Ed.), Untying the text: A post-structural anthology (pp. 48-78). Boston, MA: Routledge.

Foucault, M. (1982). The subject and power. Critical Inquiry, 8(4), 777-795.

Gergen, K. J. (2009). An invitation to social construction (2nd ed.). London, UK: Sage.

Giammattei, S. V. (2015). Beyond the binary: Trans-negotiations in couple and family therapy. Family Process, 54(3), 418-434.

Goodwin, A. M., Kaestle, C. E., \& Piercy, F. P. (2013). An exploration of feminist family therapists' resistance to and collusion with oppression. Journal of Feminist Family Therapy, 25(4), 233-256.

Hare-Mustin, R. T. (1994). Discourses in the mirrored room: A postmodern analysis of therapy. Family Process, 33, 19-35.

Helms, H. M., Walls, J. K., Crouter, A. C., \& McHale, S. M. (2010). Provider role attitudes, marital satisfaction, role overload, and housework: A dyadic approach. Journal of Family Psychology, 24(5), 568-577.

Heritage, J., \& Sefi, S. (1992). Dilemmas of advice: Aspects of delivery and reception of advice in interactions between health visitors and first time mothers. In P. Drew \& J. Heritage (Eds.), Talk at work: Interactions in institutional settings (pp. 359-417). Cambridge, UK: Cambridge University Press. 
Holstein, J. A., \& J. F. Gubrium (Eds.) (2008). Handbook of constructionist research. New York: Guilford.

Hudak, J., \& Giamattei, S. (Winter, 2010). Doing family: Decentering heteronormativity on "couple" and "family" therapy [Monograph]. American Family Therapy Academy, 49-55.

Keeling, M. L., Butler, J., Green, N., Kraus, V., \& Palit, M. (2010). The gender discourse in therapy questionnaire: A tool for training in feminist-informed therapy. Journal of Feminist Family Therapy, 22(2), 153-169.

Keeling, M. L., \& Piercy, F. (2007). A careful balance: International perspectives on culture, gender, and power in marriage and family therapy practice. Journal of Marital and Family Therapy, 33(4), 443463.

Kitzinger, C. (2009). Doing gender: A conversation analytic perspective. Gender and Society, 23(1), 94-98.

Kitzinger, C., \& Wilkinson, S. (1997). Validating women's experience? Dilemmas in feminist research. Feminism and Psychology, 7(4), 566574.

Knudson-Martin, C. (2013). Why power matters: Creating a foundation of mutual support in couple relationships. Family Process, 52, 5-18.

Knudson-Martin, C. (2015). When therapy challenges patriarchy: Undoing gendered power in heterosexual couple relationships. In C. KnudsonMartin, M. A. Wells, \& S. K. Samman (Eds.), Socio-emotional relationship therapy (pp. 15-26). New York: American Family Therapy Academy. 
Knudson-Martin, C., Huenergardt, D., Lafontant, K., Bishop, L., Schaepper, J., \& Wells, M. (2015). Competencies for addressing gender and power in couple therapy: A socio emotional approach. Journal of Marital and Family Therapy, 41(2), 205-220.

Knudson-Martin, C., \& Mahoney, A. R. (2009). Couples, gender, and power: Creating change in intimate relationships. New York: Springer.

Lawless, J. J., Gale, J. E., \& Bacigalupe, G. (2001). The discourse of race and culture in family therapy supervision: A conversation analysis. Contemporary Family Therapy, 23(2), 181-197.

Lee, E., Tsang, K. T., Bogo, M., Wilson, G., Johnstone, M., \& Herschman, J. (2017). Joining revisited in family therapy: Discourse analysis of cross-cultural encounters between a therapist and an immigrant family. Journal of Family Therapy. https://doi.org/10.1111/1467$\underline{6427.12148}$

Leslie, L. A., \& Morton, G. (2001). Family therapy's response to family diversity: Looking back, looking forward. Journal of Family Issues, 22, 904-920.

Lev, A. (2010). How queer! - The development of gender identity and sexual orientation in LGBTQ-headed families. Family Process, 49(3), 268-290.

Lock, A., \& Strong, T. (2010). Social constructionism: Sources and stirrings in theory and practice. New York: Cambridge University Press.

Lock, A, \& Strong, T. (Eds.) (2012). Discursive perspectives in therapeutic practice. London, UK: Oxford University Press. 
Maciel, J. A., van Putten, Z., \& Knudson-Martin, C. (2009). Gendered power in cultural contexts: Part I. Immigrant couples. Family Process, 48, 9-23.

Maynard, D. W. (2013). Everyone and no one to turn to: Intellectual roots and contexts for conversation analysis. In J. Sidnell \& T. Stivers (Eds.), The handbook of conversation analysis (pp. 11-31). Oxford, UK: Wiley-Blackwell.

McNamee, S., \& Gergen, K. J. (Eds.) (1992). Therapy as social construction. London, UK: Sage.

Moore, L., \& Seu, I. B. (2010). Doing family therapy: A Foucauldian discourse analysis. European Journal of Psychotherapy \& Counselling, 12(4), 323-343.

O'Reilly, M. (2014). Blame and accountability in family therapy: Making sense of therapeutic spaces discursively. Qualitative Psychology, 1(2), 163-177.

Pakes, K., \& Roy-Chowdhury, S. (2007). Culturally sensitive therapy? Examining the practice of cross-cultural family therapy. Journal of Family Therapy, 29(3), 267-283.

Parker, I. (1992). Discourse dynamics: Critical analysis for social and individual psychology. London, UK: Routledge.

Parker, L. (2009). Disrupting power and privilege in couples therapy. Clinical Social Work Journal, 37(3), 248-255.

Potter, J., \& Hepburn, A. (2005). Qualitative interviews in psychology: Problems and possibilities. Qualitative Research in Psychology, 2, 281-307. 
Potter, J., \& Hepburn, A. (2008). Discursive constructionism. In J. A. Holstein \& J. F. Gubrium (Eds.), Handbook of constructionist research (pp. 275-293). New York: Guilford.

Reynolds, C., \& Knudson-Martin, C. (2015). Gender and the construction of intimacy among committed couples with children. Family Process, 54, 293-307.

Ridgeway, C. L. (2011). Framed by gender: How gender inequality persists in the modern world. New York: Oxford University Press.

Risman, B. J. (2012). Gender as a social structure. In J. Lorber (Ed.), Gender inequality: Feminist theories and politics (5th ed., pp. 220230). New York: Oxford University Press.

Sacks, H. (1992). Lectures on conversation. (Vols. I \& II, edited by G. Jefferson). Oxford: Blackwell.

Schegloff, E. A. (1997). Whose text? Whose context? Discourse and Society, 8, 165-187.

Schegloff, E. A., \& Sacks, H. (1973). Opening up closing. Semiotica, 8, 289-327.

Shapiro, D. (2014). Stepparents and parenting stress: The roles of gender, marital quality, and views about gender roles. Family Process, 53, $97-108$.

Sidnell, J. (2010). Conversation analysis: An introduction. New York: WileyBlackwell.

Sidnell, J., \& Stivers, T. (2013). The handbook of conversation analysis. Oxford, UK: Wiley-Blackwell. 
Singh, R. (2009). Constructing 'the family' across culture. Journal of Family Therapy, 31(4), 359-383.

Speer, S. A. (2005). Gender talk: Feminism, discourse and conversation analysis. London, UK: Routledge.

Speer, S. A., \& Stokoe, E. (2011). Conversation and gender. Cambridge, UK: Cambridge University Press.

Speer, S., \& Potter, J. (2000). The management of heterosexist talk: Conversational resources and prejudiced claims. Discourse and Society, 11, 543-572.

Stokoe, E. H., \& Smithson, J. (2002). Gender and sexuality in talk-ininteraction: Considering conversation analytic perspectives. In P. Mcllvenny (Ed.), Talking Gender and Sexuality (pp. 79-110). Philadelphia: John Benjamins Publishing Company.

Stokoe, E., \& Smithson, J. (2001). Making gender relevant: Conversation analysis and gender categories in interaction. Discourse and Society, 12, 217-244.

Sunderland, J. (2004). Gendered discourses. Basingstoke, UK: Palgrave.

Sunderland, J. (2006). 'Parenting' or 'mothering'? The case of modern childcare magazines. Discourse and Society, 17(4), 503-527.

Sutherland, O. A. (2007). Therapist positioning and power in discursive therapies: A comparative analysis. Contemporary Family Therapy, 29, 193-209. 
Sutherland, O., LaMarre, A., Rice, C., Hardt, L., \& Le Couteur, A. (2017).

New sexism in couple therapy: A discursive analysis. Family Process, doi: 10.1111/famp.12292.

Sutherland, O., LaMarre, A., Rice, C., Hardt, L., \& Jeffery, N. (2016).

Gendered patterns of interaction: A Foucauldian discourse analysis of couple therapy. Contemporary Family Therapy, https://doi.org/10.1007/s10591-016-9394-6.

Tileagă, C., \& Stokoe, E. (2016). Discursive psychology: Classic and contemporary issues. London, UK: Routledge.

Toomey, R. B., Updegraff, K. A., Umaña-Taylor, A. J., \& Jahromi, L. B. (2015). Gender role attitudes across the transition to adolescent motherhood in Mexican-origin families. Family Process, 54(2), 247262.

Tseliou, E. (2013). A critical methodological review of discourse and conversation analysis studies of family therapy. Family Process, 52(4), 653-679.

van Dijk, T. A. (2001). Principles of critical discourse analysis. In M. Wetherell, S. Taylor, \& S. J. Yates (Eds.), Discourse theory and practice: $A$ reader (pp. 300-317). London, UK: Sage.

Walls, J., \& Singh, R. (2014). Constructions and enactments of whiteness: A discursive analysis. Journal of Family Therapy, 36(S1), 39-64.

Waldegrave, C. (2009). Cultural, gender, and socioeconomic contexts in therapeutic and social policy work. Family Process, 48(1), 85-102.

Ward, A., \& Knudson-Martin, C. (2012). The impact of therapist actions on the balance of power within the couple system: A qualitative analysis 
of therapy sessions. Journal of Couple and Relationship Therapy, 11, 221-237.

Weatherall, A. (2016). Interpretive repertoires, conversation analysis and being critical. In C. Tileagă \& E. Stokoe (Eds.), Discursive psychology: Classic and contemporary issues (pp. 15-28). London, UK: Routledge.

Weingarten, K. (1991). The discourses of intimacy: Adding a social constructionist and feminist view. Family Process, 30(3), 285-306.

Wetherell, M. (1998). Positioning and interpretative repertoires:

Conversation analysis and post-structuralism in dialogue. Discourse \& Society, 9(3), 387-412.

White, M., \& Epston, D. (1990). Narrative means to therapeutic ends. New York: Norton.

Wodak, R., \& Meyer, M. (Eds.) (2016). Methods of critical discourse studies (3rd ed.). London, UK: Sage. 